\title{
Aproximación general a la acción de extinción del dominio en Colombia*
}

\section{A general approach to the action of expired ownership in Colombia}

Recibido: 18 de diciembre de 2013 - Revisado: 13 de febrero de 2014 - Aceptado: 03 de abril de 2014

Jenner Alonso Tobar Torres ${ }^{* *}$

\begin{abstract}
Resumen
Colombia ha sido un país inmerso en una constante y tenaz lucha para superar un estado de violencia endémico generado por numerosos actores, entre ellos el narcotráfico y el enriquecimiento ilícito. Con el propósito de hacer frente a estos problemas, el constituyente colombiano consagró la figura de la extinción de dominio como herramienta jurídica de lucha contra el enriquecimiento ilícito, así como la violencia y pobreza que dicho fenómeno trae consigo.

26 años después, la acción de extinción de dominio es uno de los principales instrumentos del Estado para enfrentar el enriquecimiento ilícito, pero su desarrollo social y jurídico no ha sido pacífico ni totalmente efectivo. El presente artículo aborda las características generales de esta figura, exponiendo sus críticas y ventajas, y sus perspectivas de efectiva aplicación en Colombia.
\end{abstract}

\section{Palabras clave}

Derecho de propiedad, extinción de dominio, expropiación, confiscación, función social de la propiedad, reforma agraria, reparación de víctimas.

\begin{abstract}
Colombia has been a country immersed in a constant and persistent struggle to overcome a state of endemic violence generated by numerous actors, including drug trafficking and illicit enrichment. In order to address these problems, the Colombian constituent assembly consecrated the figure of expired ownership as a legal tool to combat illicit enrichment, as well as violence and poverty that this phenomenon entails. 26 years later, the action of expired ownership is one of the main instruments of the state to tackle illicit enrichment, but its social and legal development has been neither peaceful nor totally effective. This article discusses the general characteristics of this figure, exposing its criticisms and benefits, and its prospects for an effective implementation in Colombia
\end{abstract}

\section{Keywords}

Property rights, expired ownership, expropriation, confiscation, social function of property, agrarian reform, reparation to victims.

\footnotetext{
"Artículo de reflexión.

Abogado, LL.M., Universidad Nacional de Colombia. Estudiante de doctorado en Derecho Civil de la Universidad de Buenos Aires. Docente universitario.

Correo Electrónico:

jatovart@unal.edu.co.

Para citar este artículo use: Tobar, J. (2014). Aproximación general a la acción de extinción del dominio en Colombia. Revista Civilizar Ciencias Sociales y Humanas, 14(26), 17-38.
} 


\section{Introducción}

En desarrollo de la noción de función social de la propiedad, Colombia creó las figuras de extinción de dominio por no explotación de un bien y de expropiación en sus diferentes modalidades.

En respuesta a la difícil coyuntura de violencia que atravesaba la sociedad colombiana en 1991 a causa de, entre otros actores, las mafias del narcotráfico, el constituyente de 1991 estableció en el artículo 34 la extinción de dominio, desde parámetros completamente diferentes a los hasta ahora existentes en la legislación nacional:

Artículo 34. Se prohíben las penas de destierro, prisión perpetua y confiscación.

No obstante, por sentencia judicial, se declarará extinguido el dominio sobre los bienes adquiridos mediante enriquecimiento ilícito, en perjuicio del Tesoro Público o con grave deterioro de la moral social (Constitución Política, 1991).

Así pues, a partir de la Constitución de 1991, se determinó en Colombia la extinción del derecho de dominio a favor del Estado de aquellos bienes adquiridos con fondos de actividades ilícitas. La norma que en su momento reglamentaría esta potestad del Estado sería la ley 333/1996, posteriormente derogada por la ley $793 / 2002$.

Para abordar el problema de investigación del presente artículo, se pretende realizar una exposición y valoración crítica de la extinción de dominio a partir de su caracterización sustantiva y procedimental, sus bondades y desventajas en su aplicación, y con base en ello, considerar sus posibilidades de optimización en el panorama sociojurídico colombiano.

El problema de investigación se desarrollará con un enfoque eminentemente cuantitativo-deductivo, en el cual se utilizarán en ex- clusiva técnicas de investigación documental (análisis de lecturas, documentación, sentencias judiciales y estudios preexistentes sobre el tema), con el propósito de dar al lector una idea amplia de la acción de extinción de dominio y exponer algunas conclusiones sobre la información recolectada.

\section{La función social de la propiedad y la acción de extinción de dominio de tierras incultas}

En los países de tradición civilista romanista el derecho de propiedad es el eje transversal de los derechos reales, configurando el propio modelo económico de Estado, según se acepte o no la propiedad privada. En la gran mayoría de naciones, la aceptación del derecho a la propiedad privada es el común denominador, aunque también hay países con sistemas de economía central o planificada, en los cuales en menor o mayor medida, la propiedad es un derecho que recae en el Estado.

En Colombia el derecho de propiedad privada ha sido reconocido por el Estado desde las primeras constituciones independentistas (c.f. Constitución de Cundinamarca -1811-, el Pacto de Federación de las Provincias Unidas -1811-, la Constitución de Tunja-1811-, la Constitución de Antioquia -1812-, entre otras), y desde las primeras constituciones republicanas, como las de $1821,1830,1832,1842,1853,1858,1863$ y 1886 (Solano, 2004, p. 17).

En términos generales, estas constituciones reconocieron el ejercicio del derecho de propiedad a los particulares, limitándolo únicamente a la posibilidad del Estado de expropiar una propiedad particular, por motivos de interés público y mediando una justa compensación. En este sentido, la Constitución de 1886 que permaneció en vigencia por más de un siglo decretaba al respecto:

Artículo 31. Los derechos adquiridos con justo título con arreglo a las leyes civiles por 
personas naturales o jurídicas, no pueden ser desconocidos ni vulnerados por leyes posteriores.

Cuando de la aplicación de una ley expedida por motivos de utilidad pública, resultaren en conflicto los derechos de particulares con la necesidad reconocida por la misma ley; el interés privado deberá ceder al interés público. Pero las expropiaciones que sea preciso hacer requieren plena indemnización con arreglo al artículo siguiente.

Artículo 32. En tiempo de paz nadie podrá ser privado de su propiedad en todo ni en parte, sino por pena, o apremio, o indemnización, o contribución general, con arreglo a las leyes. Por graves motivos de utilidad pública, definidos por el legislador, podrá haber lugar a enajenación forzosa, mediante mandamiento judicial, y se indemnizará el valor de la propiedad, antes de verificar la expropiación.

Desde su nacimiento y durante todo el siglo XIX, el derecho de propiedad en Colombia se reconoció a los particulares sin mayores restricciones que las anotadas. Fue hasta 1936, que se dio la que tal vez es la principal reforma al derecho de propiedad en Colombia, cuando se incorporaron nuevas teorías europeas como las del jurista francés León Duguit, que repensaban el papel soberano del Estado frente a los particulares y el rol de estos respecto a la sociedad.

Es así como apareció en la escena jurídica nacional la idea de función social de la propiedad, la cual desdibujaba el derecho de propiedad como un derecho netamente subjetivo e introducía una carga a cumplir a su titular frente a la sociedad. Se rompía de esta manera con la concepción eminentemente individualista de la propiedad planteada en el Código de Napoleón. En palabras de Duguit (1915):

[...] todo individuo tiene la obligación de cumplir en la sociedad cierta función en razón directa del puesto que ocupa en ella. Por con- siguiente, el poseedor de la riqueza, por el hecho de tenerla, puede realizar cierta labor que él solo puede cumplir. Él solo puede aumentar la riqueza general, asegurar la satisfacción de las necesidades generales, al hacer valer el capital que posee (p. 55).

Una teoría de este tipo no pretendía desconocer el derecho a la propiedad privada ni acercarse a modelos socialistas, su finalidad esencial estribaba en introducir la idea de solidaridad en el derecho, para hacerlo más eficiente y para responder a las necesidades tanto individuales como colectivas. Así, a través del acto legislativo 01/1936, se fijó la función social de la propiedad en Colombia en los siguientes términos:

Artículo 10. Se garantizan la propiedad privada y los demás derechos adquiridos con justo título, con arreglo a las leyes civiles, por personas naturales o jurídicas, los cuales no pueden ser desconocidos ni vulnerados por leyes posteriores. Cuando de la aplicación de una ley expedida por motivos de utilidad pública o interés social, resultaren en conflicto los derechos de particulares con la necesidad reconocida por la misma ley, el interés privado deberá ceder al interés público o social.

La propiedad es una función social que implica obligaciones.

Por motivos de utilidad pública o de interés social definidos por el legislador, podrá haber expropiación, mediante sentencia judicial e indemnización previa.

Con todo, el legislador, por razones de equidad, podrá determinar los casos en que no haya lugar, a indemnización, mediante el voto favorable de la mayoría absoluta de los miembros de una y otra Cámara.

Esta noción de función social de la propiedad comenzó a materializarse en diversas áreas de la vida nacional, tal fue el caso de la ley 200/1936, conocida como Ley de Tierras, 
la cual consagró por primera vez en la historia colombiana la figura de la extinción de dominio.

En efecto, desde dicha Ley de Tierras el legislador colombiano dispuso la extinción o pérdida del derecho de dominio a favor de la nación sobre predios rurales, cuando se probara el abandono o la falta de explotación injustificada del dueño (incumplimiento de la función social de la propiedad) durante un lapso de diez años continuos (Solano, 2004, p. 29), término este que a través de la ley 100/1944 se amplió a quince años, y en 1973 mediante la ley 4 de dicho año se redujo a tres años.

Esta ley se consideró como uno de los primeros intentos de reforma agraria en Colombia, al perseguirse aquellos bienes que al no ser explotados, se encontraban totalmente desconectados con los requerimientos del entorno. Sin embargo, la realidad es que durante varias décadas la figura de la extinción de dominio agraria no fue aprovechada por los gobiernos de turno, siendo más empleada para propósitos agrarios o de desarrollo urbano la figura de la expropiación.

La expropiación señala la pérdida del derecho de propiedad por razones específicas fijadas por la Constitución o la ley, en especial, motivos de utilidad pública, interés social, o de equidad, y con previa indemnización al propietario, adelantándose mediante proceso administrativo o judicial. Empero, excede a nuestro objeto de trabajo un análisis en detalle de la expropiación, por lo cual no profundizaremos sobre tal figura.

La idea de función social de la propiedad continuó arraigándose en el derecho colombiano en las décadas siguientes, de tal suerte que en el nuevo pacto constitucional de 1991 el constituyente reconoció esta, a la que se le agregaría una función ecológica:

Artículo 58. Se garantizan la propiedad privada y los demás derechos adquiridos con arreglo a las leyes civiles, los cuales no pueden ser desconocidos ni vulnerados por leyes posteriores. Cuando de la aplicación de una ley expedida por motivos de utilidad pública o interés social, resultaren en conflicto los derechos de los particulares con la necesidad por ella reconocida, el interés privado deberá ceder al interés público o social.

La propiedad es una función social que implica obligaciones. Como tal, le es inherente una función ecológica.

El Estado protegerá y promoverá las formas asociativas y solidarias de propiedad.

Por motivos de utilidad pública o de interés social definidos por el legislador, podrá haber expropiación mediante sentencia judicial e indemnización previa. Esta se fijará consultando los intereses de la comunidad y del afectado. En los casos que determine el legislador, dicha expropiación podrá adelantarse por vía administrativa, sujeta a posterior acción contenciosa-administrativa, incluso respecto del precio.

En este sentido, actualmente la ley 160/1994 consagra la extinción de dominio sobre los predios rurales en los que se deja de ejercer posesión en la forma establecida en el artículo 1 de la ley 200/1936 ${ }^{1}$, esto es, la explotación económica durante tres años continuos, y sobre aquellos bienes con destino a la explotación con cultivos ilícitos².

La extinción de dominio por no explotación económica, conocida como extinción de dominio agrario o de tierras incultas, le corresponde adelantarla al Instituto Colombiano de Desarrollo Rural (Incoder) mediante procedimiento administrativo, de conformidad con lo que fija la ley 160/1994 en el numeral 14 del artículo 12 y el artículo 52 de la misma ley ${ }^{3}$, el numeral 6 del artículo 20 del decreto 3759/2009, así como lo dispuesto en el decreto 2665/1994, en donde se reglamenta el procedimiento de la declaratoria de extinción de dominio agrario, 
consagrando como causales de tal procedimiento las siguientes:

Artículo 2. Causales de extinción del derecho del dominio. Será procedente la declaración administrativa de extinción del derecho de dominio o propiedad en los siguientes casos:

1. Respecto de los predios rurales en los cuales se deja de ejercer la posesión en las condiciones previstas en el artículo 1 de la ley 200/1936, durante tres (3) años continuos. Lo dispuesto en este numeral no impide la declaratoria de extinción del derecho de dominio, cuando a la fecha de promulgación de la ley 160/1994 hubiere transcurrido un lapso de tres (3) años de inexplotación del inmueble, o si ese término se cumpliere dentro de la vigencia de esta norma. Cuando la posesión se hubiere ejercido sobre una parte del predio solamente, la extinción del dominio no comprenderá sino las porciones incultas que no se reputen poseídas conforme a la ley 200/1936.

2. Cuando se violen las disposiciones sobre conservación, mejoramiento y utilización racional de los recursos naturales renovables, y las de preservación y restauración del ambiente contempladas en el Código Nacional de Recursos Naturales Renovables y de Protección al Medio Ambiente, la ley 99/1993 y demás normas pertinentes sobre la materia.

3. Cuando los propietarios infrinjan las normas sobre zonas de reserva agrícola o forestal establecidas en los planes de desarrollo de los municipios o distritos con más de 300.000 habitantes.

4. El previsto en el inciso 2 del artículo 52 de la ley $160 / 1994$.

La Corte Constitucional colombiana expresa que al momento de adelantar este procedimiento de extinción de dominio, se debe dar especial protección a los habitantes de los predios objeto de la acción, de tal forma que se asegure que con la declaratoria de extinción de dominio no se vaya a propiciar o reforzar fe- nómenos de desplazamiento forzado (sentencia T-076/2011).

\section{La acción de extinción de dominio por enriquecimiento ilícito}

Como se manifestó en la introducción de este trabajo, en 1991 el constituyente erigió una acción de extinción de dominio con parámetros totalmente distintos a los que hasta entonces se conocían en el panorama jurídico nacional. Esta figura sui géneris se creó desde el propio texto constitucional con el fin específico de combatir el narcotráfico y el enriquecimiento ilícito, de tal suerte que tratándose de una acción real, requiere para su ejecución investigaciones de características penales. En palabras del exmagistrado de la Corte Constitucional José Gregorio Hernández Galindo (2005):

Esta figura novedosísima que se plasmó en el artículo 34, implica sencillamente que, aunque en apariencia una propiedad mueble o inmueble en zonas rurales o en zonas urbanas, está en cabeza de unas personas, realmente nunca llegó a radicarse en su cabeza, porque se adquirió por enriquecimiento ilícito o se adquirió con grave deterioro a la moral social que plasma la Constitución, o se adquirió con lesión del patrimonio estatal. Esas figuras están enmarcadas dentro del concepto de extinción de dominio porque precisamente, lo que quiso el constituyente fue reaccionar contra esa propiedad, muy extendida en el territorio, en cabeza de personas que habían cometido crímenes, delitos, acciones completamente injustas contra la sociedad colombiana y que se habían apoderado, o se están apoderando de gran parte del territorio nacional (p. 64).

Frente a la naturaleza de la acción de extinción de dominio aparece que esta es una acción de naturaleza constitucional, al consagrarse desde el propio texto de la Constitución por el propio constituyente.

También es una acción autónoma, pues no se enmarca dentro del ejercicio del ius puniendi del Estado, toda vez que lo que se pre- 
tende no es determinar la responsabilidad penal del individuo, pues esta se adelanta con autonomía de la acción de extinción de dominio, ni se procura aplicar una pena contra la persona. La finalidad de esta acción radica en destruir el velo de aparente legalidad que recae sobre el derecho de dominio de un bien, derecho que por su origen ilegal nunca ha nacido, pero que goza de apariencia de legitimidad.

En la medida que la extinción de dominio se realiza sin contraprestación ni compensación de naturaleza alguna para su titular, esta figura ha sido asimilada a la confiscación; no obstante, el elemento diferenciador entre esta y la extinción de dominio, radica en el hecho de que la última no se trata de una pena en cuya virtud se prive a la persona de un derecho que tenía.

Así, con la extinción de dominio no se persigue una condena sino una sentencia declarativa acerca de la inexistencia del derecho aparente que se ostentaba, cuyos efectos necesariamente se proyectarán retroactivamente al momento de la supuesta y desvirtuada adquisición de aquel derecho.

En efecto, como no existe ningún derecho adquirido de quien figura como titular de la propiedad, entonces mal puede hablarse de indemnizar al sujeto afectado por la sentencia, o de compensar de alguna forma y en cualquier medida la disminución que por tal motivo se produzca en su patrimonio (Hernández, 2005, p. 64). Al respecto, la Corte Constitucional señaló:

Resulta muy ilustrativa la expresión utilizada por el constituyente antes de fijar la regla de derecho consagrada en el inciso segundo: "No obstante...". Es decir, se prohíbe la pena de confiscación entendida como la pérdida del patrimonio a favor del Estado pero ello no se opone a que, sin carácter punitivo y por sentencia judicial, se extinga el dominio de los bienes adquiridos mediante alguno de los mecanismos fijados por el constituyente. O lo que es lo mismo, el mandato para que se haga tal declaración judicial se imparte porque la extinción de dominio no constituye una pena de confiscación pues esta está proscrita.

De acuerdo con esto, la acción de extinción de dominio no fue asumida por el constituyente como una pena sino como una acción constitucional pública, jurisdiccional, autónoma, directa y expresamente regulada por el constituyente y su ubicación en el artículo 34 superior se explica en razón de la estrecha relación existente entre ella y el derecho de propiedad. En tal virtud, la naturaleza y el alcance de la acción de extinción de dominio no deben determinarse en el contexto del poder punitivo del Estado (sentencia, C-740/2003).

De este modo, la acción de extinción de dominio lejos de ser una acción de naturaleza penal, es una acción real en tanto que no persigue a la persona, sino a la cosa misma, a los bienes que provienen de actividades delictivas o que se han empleado como medios o instrumentos para la realización de las mismas (sentencia extinción de dominio, 21 de septiembre de 1999).

Así mismo, vale mencionar que tanto la expropiación, la extinción de dominio sobre tierras incultas y la extinción de dominio sobre bienes adquiridos a través de enriquecimiento ilícito, son figuras que difieren totalmente de la confiscación.

Laconfiscaciónimplicaeldespojoabsoluto de los bienes de una persona a título de sanción penal, existiendo consenso internacional frente a su proscripción por considerarse violatoria de los derechos humanos. Colombia no es la excepción, y desde el texto constitucional en su artículo 34 se prohíbe la confiscación.

Ahora bien, no por el hecho de ser una acción real puede tomarse como una acción estrictamente civil, por cuanto si bien es una acción de carácter patrimonial esta no está motivada por intereses patrimoniales de particulares, sino que responde a un interés superior del Estado, consistente en desvirtuar la existencia de un derecho de propiedad ilícitamente adqui- 
rido, y que en consecuencia no puede gozar de la protección jurídica del Estado.

Es decir, la extinción del dominio ilícitamente adquirido no es un instituto que se circunscribe a la órbita patrimonial del particular afectado con su ejercicio, pues, lejos de ello, se trata de una institución asistida por un legítimo interés público (sentencia C-740/2003).

Pese a no ser una acción de naturaleza eminentemente civil, sí es una acción que se encuentra estrechamente relacionada con el régimen constitucional del derecho de propiedad, y así lo reconoce la Corte Constitucional al expresar que:

A través de ella el constituyente estableció el efecto sobreviniente a la adquisición, solo aparente, de ese derecho por títulos ilegítimos. Esto es así, al punto que consagra varias fuentes para la acción de extinción de dominio y todas ellas remiten a un título ilícito. Entre ellas está el enriquecimiento ilícito, prescripción que resulta muy relevante, pues bien se sabe que el ámbito de lo ilícito es mucho más amplio que el ámbito de lo punible y en razón de ello, ya desde la Carta la acción de extinción de dominio se desliga de la comisión de conductas punibles y se consolida como una institución que desborda el marco del poder punitivo del Estado y que se relaciona estrechamente con el régimen del derecho de propiedad (sentencia C-740/2003).

Además, esta es una acción pública, judicial y directa. Pública por cuanto obedece a intereses superiores del Estado como lo es la protección al patrimonio público, el tesoro público y la moral social; judicial en la medida que con ella se busca desvirtuar la legitimidad del derecho de dominio sobre unos bienes, y en consecuencia, su ejercicio debe gozar de todas las garantías judiciales; directa porque su procedencia se supedita únicamente a la demostración de uno de los supuestos consagrados por el constituyente: enriquecimiento ilícito, perjuicio del tesoro público o grave deterioro de la moral social.
Como se observa, dada su especial naturaleza, la acción de extinción de dominio se somete a fines y características muy particulares, y por ende, no puede asimilarse de lleno a una acción penal o civil, pese a que tenga elementos de contacto con una y otra. Por el objeto sobre el cual recae (el bien y el derecho de dominio) se aproxima al campo civil, por sus causas y su finalidad (perseguir los bienes obtenidos por enriquecimiento ilícito, perjuicio del tesoro público o grave deterioro de la moral social) tiene puntos de encuentro con lo penal.

\section{Tratamiento legislativo y procesal de la ac- ción de extinción de dominio}

El constituyente no estableció qué jurisdicción era la competente para conocer de la acción de extinción de dominio. Esto, junto con el procedimiento de la misma, fue definido por el legislador.

El tratamiento legislativo de la extinción de dominio ha atravesado por tres momentos: el primero empezó con la ley 333/1996, que fue la primera ley que reglamentó los aspectos sustanciales y procesales de la figura; una segunda etapa a partir de la ley 793/2002 -modificada por la ley 1453/2011- que derogó a su antecesora y en la cual la extinción de dominio ha ejercido su mayor impacto en el país; y finalmente un tercer momento que se encuentra a punto de iniciar con la ley 1708/2014, a través de la cual se expide el Código de Extinción de Dominio (en adelante CED) y cuya entrada en vigencia se dará después del 20 de julio de 2014, cuando se cumplan seis meses desde su promulgación.

Recientemente se promulgó la ley 1708/2014 "por la cual se expide el Código de Extinción de Dominio", que deroga las leyes 793/2002, 785/2002 y 1330/ 2009 y que dispuso de un régimen de transición por medio de su artículo 271, el cual decretó que:

Los procesos en que se haya proferido resolución de inicio con fundamento en las causales 
que estaban previstas en los numerales 1 al 7 de la ley 793/2002, antes de la expedición de la ley 1453/2011, seguirán rigiéndose por dichas disposiciones.

De igual forma, los procesos en que se haya proferido resolución de inicio con fundamento en las causales que estaban previstas en el artículo 72 de la ley 1453/2011, seguirán rigiéndose por dichas disposiciones (ley 1708/2014, art. 271).

Así las cosas, es totalmente previsible que durante varios años más la ley 793/2002 continúe irradiando sus efectos en el ordenamiento jurídico nacional, hasta tanto no finalicen los procesos iniciados desde su imperio 5 . Por tal motivo, a continuación se efectuará un breve repaso de algunos de los principales aspectos procesales de la ley $793 / 2002$, para posteriormente resaltar las modificaciones que introdujo la ley 1708/2014.

\section{El procedimiento de extinción de dominio en la ley 793/2002}

La ley 793/2002 otorgó la competencia para conocer sobre la acción de extinción de dominio a la Fiscalía General de la Nación (art. 11), y así mismo determinó que esta acción puede iniciarse de oficio por esa entidad o por cualquier persona (art. 5). Grosso modo el procedimiento es el que se presenta a continuación.

Al avocar conocimiento de la acción, la Fiscalía debe iniciar la correspondiente investigación para identificar los bienes sobre los cuales podría recaer la acción, recaudando los medios de prueba que evidencien cualquiera de las siguientes situaciones:

Artículo 2o. Causales. Se declarará extinguido el dominio mediante sentencia judicial, cuando ocurriere cualquiera de los siguientes casos:

1. Cuando exista incremento patrimonial injustificado, en cualquier tiempo, sin que se explique el origen lícito del mismo.
2. Cuando el bien o los bienes de que se trate provengan directa o indirectamente de una actividad ilícita.

3. Cuando los bienes de que se trate hayan sido utilizados como medio o instrumento para la comisión de actividades ilícitas, sean destinadas a estas o correspondan al objeto del delito.

4. Cuando los bienes o recursos de que se trate provengan de la enajenación o permute de otros que tengan su origen, directa o indirectamente, en actividades ilícitas, o que hayan sido destinados a actividades ilícitas o sean producto, efecto, instrumento u objeto del ilícito.

5. Cuando los bienes de que se trate tengan origen lícito, pero hayan sido mezclados, integrados o confundidos con recursos de origen ilícito. Se exceptúan los títulos depositados en los Depósitos Descentralizados de Valores, siempre y cuando los tenedores de esos títulos cumplan satisfactoriamente las normas en materia de prevención del lavado de activos y financiación del terrorismo que le sean exigibles (ley $793 / 2002$, art. 2 , modificado por la ley 1453/2011, art. 72).

Si la Fiscalía considera que existen suficientes elementos probatorios que señalen la posible existencia de bienes objeto de extinción de dominio, proferirá resolución de inicio de extinción de dominio y notificará de ella a los interesados, posteriormente abrirá período probatorio de treinta días, y se procederá a presentar alegatos de conclusión en un término de cinco días. Al finalizar este proceso, la Fiscalía dictará resolución declarando la procedencia o improcedencia de la acción de extinción de dominio, ante la cual procede recurso vertical de apelación (ley 793/2002, art. 13).

En todo momento del procedimiento se debe respetar el derecho de defensa y debido proceso de los interesados, quienes tendrán la potestad de demostrar el origen lícito de los bienes objeto de investigación (ley 793/2002, arts. 8 y 9 ). 
Así mismo, si bien la presunción de inocencia es una garantía propia de los procesos penales, por lo cual no es directamente aplicable a la acción de extinción de dominio, en esta tampoco hay lugar a presumir la ilícita procedencia de los bienes que son objeto de ella, pues el Estado, a través de las autoridades competentes, tiene el deber de demostrar esa ilícita procedencia, actividad en la cual el afectado tiene todo el derecho de ejercer su defensa (sentencia C-740/2003).

Una vez en firme la resolución que declara la procedencia de la acción de extinción de dominio, esta se remitirá al correspondiente juez penal del Circuito Especializado de Extinción de Dominio de Bogotá, el cual proferirá la respectiva sentencia declarando o no la extinción de dominio de los bienes involucrados.

Dicho fallo es apelable ante la Sala de Extinción de Dominio del Tribunal Superior del Distrito Judicial de Bogotá. En cualquier caso, la sentencia de primera instancia que niegue la extinción de dominio y que no sea apelada, se someterá en todo caso a grado jurisdiccional de consulta (ley 793/2002, arts. 11, 13).

Por otra parte, a través de la ley 1330/2009 "por la cual se adiciona la ley 793/2002 y se establece el trámite abreviado y el beneficio por colaboración", se agregó al procedimiento ya indicado, un mecanismo especial para el caso de aquellas personas que pretendan efectuar con la Fiscalía un acuerdo de entrega voluntaria de bienes para que se profiera sentencia anticipada de extinción del dominio, caso en el cual la persona podrá obtener beneficios que le permitan una vivienda para sí, o sus familiares, cuyo valor oscilará entre el $0,1 \%$ y el $5 \%$ del costo total de los bienes efectivamente entregados (ley 1330/2009, art. 5).

\section{El nuevo Código de Extinción de Dominio: la ley 1708/2014}

Como ya se enunció, a través de la mencionada ley 1708/2014 se creó el CED, el cual entrará en vigencia a partir del 20 de julio de 2014 para gobernar todos los procesos e investigaciones de extinción de dominio que inicien desde tal fecha, pues como se expresó, los que empezaron con la anterior ley 793/2002, proseguirán su curso desde tal normatividad.

Lo primero que se resalta del nuevo CED es que no se modificó en absoluto la naturaleza de la figura y de la acción, dándose continuidad a la misma estructura jurídica de la ley 793/2002 y a los lineamientos jurisprudenciales de la Corte Constitucional en la materia.

En nuestra opinión, el CED incorpora dos grandes novedades: por una parte, recopila en un solo cuerpo normativo el universo legislativo y jurisprudencial preexistente en la materia, y por otra, realiza importantes cambios en aspectos procedimentales.

Respecto al primer punto, con el CED se integran en un solo texto legislativo situaciones antes reguladas a través de las leyes 793/2002, 1330/2009, 1395/2010 y 1453/2011; el Código de Procedimiento Penal (ley 906/2004) y el Código de Procedimiento Civil, y así mismo, se recogen los lineamientos jurisprudenciales efectuados por la Corte Constitucional en pronunciamientos como las sentencias C-374/1997, C-740/2003, C-030/2006, C-887/2004, C-296/ 2011, C-540/2011, entre otras, algunas de las cuales ya se citaron aquí (Congreso de la República de Colombia, Gaceta del Congreso, 724, 16 de septiembre de 2013).

El CED incorporó una serie de principios y normas rectoras aplicables a la extinción de dominio, los cuales responden a los diversos pronunciamientos que en tal sentido había realizado la Corte Constitucional. Así las cosas, se tiene como tales la dignidad, el derecho de propiedad, el debido proceso, el principio de objetividad y transparencia, el principio de contradicción, la presunción de buena fe, la autonomía e independencia judicial, la publicidad, la doble instancia, la cosa juzgada, 
entre otros, cuyo contenido desarrolla el CED (ley 1708/2014, arts. 2-14).

Gracias a este importante trabajo, tanto la figura de extinción de dominio como su acción, se reconceptualizaron a partir de los parámetros legislativos y jurisprudenciales preexistentes y así mismo, las causales se revisaron y desagregaron para superar problemas de interpretación que se habían suscitado con respecto a la ley 793/2003 (Martínez, 2014). En este sentido, la extinción de dominio se redefinió como:

La extinción de dominio es una consecuencia patrimonial de actividades ilícitas o que deterioran gravemente la moral social, consistente en la declaración de titularidad a favor del Estado de los bienes a que se refiere esta ley, por sentencia, sin contraprestación ni compensación de naturaleza alguna para el afectado (ley 1708/2014, art. 15).

Por su lado, la acción de extinción de dominio fue caracterizada así:

La acción de extinción de dominio de que trata la presente ley es de naturaleza constitucional, pública, jurisdiccional, directa, de carácter real y de contenido patrimonial, y procederá sobre cualquier bien, independientemente de quien lo tenga en su poder o lo haya adquirido.

Esta acción es distinta y autónoma de la penal, así como de cualquiera otra, e independiente de toda declaratoria de responsabilidad.

En ningún caso procederá la prejudicialidad para impedir que se profiera sentencia, ni incidentes distintos a los previstos en esta ley (ley 1708/2014, arts. 17 y 18).

Como se observa, tanto la figura como la acción mantienen los atributos a los que nos referimos en páginas anteriores. Ahora bien, respecto a las causales, el CED determinó que procede la extinción de dominio ante los siguientes eventos:
Artículo 16. Causales. Se declarará extinguido el dominio sobre los bienes que se encuentren en las siguientes circunstancias:

1. Los que sean producto directo o indirecto de una actividad ilícita.

2. Los que correspondan al objeto material de la actividad ilícita, salvo que la ley disponga su destrucción.

3. Los que provengan de la transformación o conversión parcial o total, física o jurídica del producto, instrumentos u objeto material de actividades ilícitas.

4. Los que formen parte de un incremento patrimonial no justificado, cuando existan elementos de conocimiento que permitan considerar razonablemente que provienen de actividades ilícitas.

5. Los que hayan sido utilizados como medio o instrumento para la ejecución de actividades ilícitas.

6. Los que de acuerdo con las circunstancias en que fueron hallados, o sus características particulares, permitan establecer que están destinados a la ejecución de actividades ilícitas.

7. Los que constituyan ingresos, rentas, frutos, ganancias y otros beneficios derivados de los anteriores bienes.

8. Los de procedencia lícita, utilizados para ocultar bienes de ilícita la procedencia.

9. Los de procedencia lícita, mezclados material o jurídicamente con bienes de ilícita procedencia.

10. Los de origen lícito cuyo valor sea equivalente a cualquiera de los bienes descritos en los numerales anteriores, cuando la acción resulte improcedente por el reconocimiento de los derechos de un tercero de buena fe exenta de culpa.

11. Los de origen lícito cuyo valor corresponda o sea equivalente al de bienes producto 
directo o indirecto de una actividad ilícita, cuando no sea posible la localización, identificación o afectación material de estos.

Parágrafo. También procederá la extinción de dominio respecto de los bienes objeto de sucesión por causa de muerte, cuando en ellos concurra cualquiera de las causales previstas en esta ley (ley 1708/2014, art. 16).

Vale decir, que el concepto de actividad ilícita también lo precisó el CED como "toda aquella [actividad ilícita] tipificada como delictiva, independiente de cualquier declaración de responsabilidad penal, así como toda actividad que el legislador considere susceptible de aplicación de esta ley por deteriorar la moral social" (ley 1708/2014, art. 1). Si se observa detenidamente las nuevas causales, se encontrará que se efectuó una nueva redacción pormenorizada de las situaciones ya contenidas en la ley 793/2002, esto para facilitar su aplicación y superar problemas de interpretación.

Como ya se manifestó, las principales modificaciones del CED son de contenido procesal. Por cuestiones de espacio no se hará un análisis minucioso de estas y en su lugar, nos limitaremos a resaltar tan solo algunas consideraciones generales respecto a los cambios que se introdujeron.

La estructura del proceso y la competencia se mantienen idénticas. Existe una primera etapa de investigación a cargo de la Fiscalía General de la Nación, y una etapa judicial a cargo de la Sala de Casación Penal de la Corte Suprema de Justicia, las salas de extinción de dominio de los tribunales superiores de distrito judicial y los jueces del circuito especializados en extinción de dominio. Solamente se agregan reglas respecto a competencia funcional y territorial que recoge lo establecido en los códigos de procedimiento civil y penal.

En la fase inicial de investigación, la Fiscalía podrá adelantar por sí misma o a través de orden emitida a los servidores que cumplan funciones de policía judicial, todos los actos de investigación que considere necesarios y conducentes para cumplir los fines constitucionales y legales de la acción de extinción de domino.

La fase inicial puede terminar con una resolución de archivo del proceso, si se considera que no existe causal alguna de extinción, o con una resolución de fijación provisional de la pretensión de extinción. Una vez efectuada la resolución de fijación provisional, el afectado es comunicado y tiene derecho de ejecutar su oposición, al término del traslado, la Fiscalía deberá presentar ante el juez competente el requerimiento de extinción de dominio o de declaratoria de improcedencia.

Una vez el afectado es notificado de la resolución de fijación provisional, puede acogerse a sentencia anticipada a través de un mecanismo abreviado dispuesto para la etapa de juicio en este caso, y así podrá hacerse acreedor de una retribución de hasta un $3 \%$ del valor de los bienes que sean objeto de sentencia anticipada.

Se adicionan normas sobre requisitos formales de las providencias y normas sobre notificación y nulidades de las actuaciones desarrolladas. Así mismo, se incorporan reglas sobre los recursos procedentes contra las providencias de los jueces de extinción de dominio, particularmente los de reposición, apelación y queja, y se establecen disposiciones para el trámite de la acción de revisión en este tipo de procesos. También el CED crea un régimen probatorio propio, que incluye reglas sobre la vigilancia de cosas, personas e información tecnológica.

A su vez se crean normas sobre la procedencia de las medidas cautelares de embargo, secuestro y toma de posesión de bienes, haberes y negocios de sociedades, establecimientos de comercio o unidades de explotación económi$\mathrm{ca}^{6}$, las cuales proceden por regla general en la etapa judicial, no obstante, se le da la potestad a la Fiscalía de que previo a proferir la resolu- 
ción de fijación provisional de la pretensión, en casos de evidente urgencia o cuando existan serios motivos fundados que permitan considerar como indispensable y necesario, pueda imponer medidas cautelares, que no podrán durar más de seis meses, en los cuales deberá archivar la investigación o proferir la resolución de fijación.

La imposición de medidas cautelares por parte de la Fiscalía en la etapa inicial no es susceptible de recursos, aunque puede ser objeto de control de legalidad ante los jueces de extinción de dominio, previa solicitud motivada del afectado, del Ministerio Público o del Ministerio de Justicia y del Derecho. Este control de legalidad no solamente procede contra la imposición de medidas cautelares, sino también contra el archivo y los actos de investigación.

\section{Claros y oscuros de la acción de extinción del dominio}

Una vez expuesta la naturaleza de la acción de extinción de dominio por enriquecimiento ilícito, y sus características principales en cuanto al procedimiento que se debe adelantar para el efecto, nos centraremos en las más importantes críticas y defensas que de este instituto se han realizado, críticas que van desde su inconstitucionalidad hasta su ineficiencia práctica.

En lo que respecta a las primeras, se ha señalado la incoherencia que existe al entregar el ejercicio de una acción real y patrimonial al ente encargado de adelantar la acción penal. En principio, al considerarse que la acción de extinción de dominio es de carácter real, patrimonial y estrechamente vinculada con el derecho de propiedad, podría pensarse que el juez natural de esta acción es el juez civil. Sin embargo, la Corte Constitucional no encontró reparo en que el legislador haya otorgado la competencia de esta acción a la Fiscalía General de la Nación y a los jueces penales especializados.
En efecto, en el examen de constitucionalidad de la norma (sentencia C-740/2003), la Corte justificó la competencia de la Fiscalía especialmente en razón al vínculo entre las conductas que exigen ser investigadas para la procedencia de la extinción de dominio y las labores propias de la Fiscalía.

La Corte indicó que en la medida que el constituyente no estableció el órgano jurisdiccional que debía adelantar la acción de extinción de dominio, correspondió al legislador otorgar esta competencia, eligiendo para ello a la Fiscalía General de la Nación.

A juicio de la Corte esa elección no se opone a la Constitución, en tanto que la misma le otorga a la Fiscalía una serie de funciones que no solamente se limitan al ejercicio de la acción penal, sino que se extienden a participar en la configuración de la política criminal del Estado, y cumplir "las demás funciones que establezca la ley", siempre y cuando estas se relacionen con su llamado misional.

En este sentido, para la Corte es claro que la acción de extinción de dominio exige una investigación de conductas que eventualmente pueden llegar a ser consideradas delitos, como lo es el enriquecimiento ilícito.

Esto, sumado a que la Fiscalía General de la Nación es una entidad que administra justicia y que forma parte de la Rama Judicial, lleva a la Corte a considerar esta entidad como la más adecuada para investigar las conductas que dan lugar a las causales de extinción de dominio, pues dichas causales remiten a la comisión de conductas punibles, independientemente de que la responsabilidad penal llegue o no a establecerse en el respectivo proceso penal.

Por lo anterior, la elección del legislador al conceder la competencia a este órgano, resulta no solo legítima, sino razonable, de acuerdo con la labor adelantada por la Fiscalía. 
Ahora bien, en cuanto a que es la Fiscalía quien investiga las conductas que pueden dar lugar a la extinción de dominio por enriquecimiento ilícito, el legislador determinó que el juez competente para dictar la correspondiente sentencia sería un juez penal especializado de extinción de dominio.

De este modo, pese a que el objeto de la acción recae sobre bienes y se discute la existencia o no del derecho de dominio bajo causales de cuestionamiento específicas, el legislador prefirió adjudicar la competencia de esta acción al ente especializado en la investigación de las conductas contenidas en dichas causales: el juez natural, para dirimir los conflictos suscitados respecto a los bienes y el derecho de propiedad.

Esta elección legislativa se encuentra lógica en tanto que resulta mucho más cómodo para la Fiscalía, el ente estatal responsable de investigar las conductas punibles, instituir la posible configuración de las causales que dan lugar a la extinción de dominio y presentar su acusación ante el juez penal especialista en la materia, que para un juez civil entrar a definir si cierta conducta configura o no una actividad ilícita, independientemente de que con ello no se esté determinando responsabilidad penal alguna.

Para la Corte, resultaría contrario al ordenamiento constitucional que se asignara el conocimiento de esta acción a una autoridad judicial diferente a la Fiscalía, haciéndose caso omiso al hecho de que esta debe investigar las conductas que dan lugar a la extinción de dominio. De ser así, se quebrantaría el imperativo de diligencia a que deben sujetarse los procesos judiciales -artículo 228 de la Constitución Política- y se desconocería el principio de economía que debe caracterizar dichas actuaciones -artículo 229 de la Constitución Política- (sentencia C-1708/2000).

El tratadista Pedro Pablo Camargo, férreo crítico de la acción de extinción de dominio, sostiene que de la manera en que el legislador implantó esta figura es en realidad un modo de confiscación. Dicho autor asevera que para atacar y desvirtuar los títulos aparentes, el derecho civil consagró la figura de la acción reivindicatoria mediante la cual el propietario puede recuperar la propiedad adquirida por medios ilegales.

El ejercicio de la acción reivindicatoria corresponde al que tiene la propiedad plena o nuda, absoluta o fiduciaria de la cosa (Código Civil Colombiano, art. 950) y no al Estado, pues este, solo es propietario del subsuelo y de los recursos naturales no renovables (Constitución Política de Colombia, art. 332). De tal suerte que al asignar competencia a jueces penales y legitimar al Estado, Pedro Pablo Camargo estima que se consagra una forma de confiscación.

Nos parece satisfactoria la respuesta que brindó la Corte en la sentencia C- 740/2003 a este argumento, reiterado en la sentencia C-540/2011. La Corte acierta al manifestar que la acción reivindicatoria es una institución legal concebida como mecanismo para proteger al propietario de una cosa singular de la que no está en posesión, para que el poseedor sea condenado a restituirla.

En las hipótesis de procedibilidad para la extinción de dominio, se efectuó un contrato de compraventa entre un vendedor y un comprador, formándose un "aparente" contrato perfecto: título (contrato de compraventa) y modo (tradición). El vicio del contrato se encuentra en el origen ilícito de los fondos con los cuales el comprador adquirió la propiedad del bien, de tal manera que es en el título donde se halla el vicio que impide el nacimiento del derecho de dominio.

En este sentido, el vendedor no puede considerarse como propietario en la medida que, de buena fe, trasladó el dominio de su bien a cambio de una contraprestación económica, que efectivamente recibió. Ahora bien, si este 
vendedor conocía del origen ilícito de los fondos con los que le fue pagada su prestación, en este caso la contraprestación recibida también sería susceptible de extinción de dominio, además de la eventual responsabilidad penal por el punible de lavado de activos.

Si el vendedor actuó de buena fe al transmitir su derecho de dominio a alguien que lo adquirió con fondos ilícitos, no le es posible al primero predicarse como propietario e iniciar la acción reivindicatoria del bien aun si posteriormente se quiebra la buena fe inicial, pues en el momento del contrato el vendedor manifestó su intención de trasladar su derecho de dominio a cambio del precio pactado, el cual recibió.

Por parte del comprador, es claro que el Estado no puede proteger derechos adquiridos de manera ilegítima, como bien lo expone la Corte:

No tendría ningún sentido la concepción del Estado como social de derecho y, en consecuencia, como Estado de justicia; ni la inclusión del valor superior justicia en el Preámbulo de la Carta, ni la realización de un orden social justo como uno de los fines del Estado, ni la detenida regulación de la libertad y de la igualdad como contenidos de la justicia; si se permitiera, por una parte, que se adquieran derechos mediante títulos ilegítimos $\mathrm{y}$, por otra, que esos derechos ilícitamente adquiridos fueran protegidos por la Constitución misma. Por el contrario, la concepción del Estado, sus valores superiores, los principios, su régimen de derechos y deberes, imponen, de manera irrefutable, una concepción diferente: los derechos solo se pueden adquirir a través de mecanismos compatibles con el ordenamiento jurídico y solo a estos se extiende la protección que aquel brinda (Corte Constitucional, sentencia C-740/2003).

Por otra parte, hasta este momento no se ha puesto de presente que la acción de extinción de dominio protege a los terceros de buena fe exenta de culpa. De este modo, "quien ha adquirido un bien desconociendo, pese a la prudencia de su obrar, su ilegítima procedencia, no puede ser afectado con la extinción del dominio así adquirido" (sentencia C-740/2003). Esta acción únicamente se justifica cuando el comprador adquiere su dominio aparente por medios ilegítimos, a sabiendas de ello.

En este sentido, las características de la acción reivindicatoria no permiten enfrentar la situación jurídica que se presenta en las causales de la acción de extinción de dominio, pues como se ya se mencionó, esta acción surge con características especiales para responder a un fenómeno particular y concreto: la lucha contra el enriquecimiento ilícito, el narcotráfico y la protección del tesoro público.

La propia ley 793/2002 y la Corte Constitucional enuncian de manera fehaciente, que la acción de extinción de dominio es un procedimiento totalmente independiente de cualquier proceso penal contra el afectado. El artículo 4 de dicha ley, declara que la acción de extinción de dominio "es distinta e independiente de cualquier otra de naturaleza penal que se haya iniciado simultáneamente, o de la que se haya desprendido, o en la que tuviera origen, sin perjuicio de los terceros de buena fe exentos de culpa". Empero, en la práctica esto resulta claro, pues como expone Camargo (2009):

Si el dominio se ha adquirido por actos de enriquecimiento ilícito, se trata de una conducta delictuosa que apareja la extinción del bien así adquirido pero mediante sentencia judicial en firme en que se haya establecido la responsabilidad individual del titular aparente del bien y, obviamente, el origen ilícito del bien. Una cosa con la otra están indisolublemente ligadas (p. 88).

Pese a que se pretende sostener que con la acción de extinción de dominio no se atribuye responsabilidad penal alguna al afectado, materialmente en la sentencia que declara la 
extinción de dominio, se reconoce de modo implícito la responsabilidad penal del individuo que da origen a la consecuente extinción de dominio.

Esto puede aparejar problemas tanto de orden constitucional como práctico. En primer lugar, al juzgarse las actividades de enriquecimiento ilícito de un individuo en dos procesos diferentes, se está vulnerando el principio fundamental de non bis in idem, pues aunque en el proceso de extinción de dominio no se fija formalmente responsabilidad penal y lógicamente no se impone pena alguna, en la parte motiva de la sentencia sí se establece que el afectado incurrió en alguna de las causales de extinción de dominio, las cuales aparejan una responsabilidad penal.

En este orden de ideas, resulta apenas lógico que si las causales de extinción de dominio conllevan de suyo una responsabilidad penal, la extinción de dominio solamente debería proceder al establecerse dicha responsabilidad mediante sentencia condenatoria en firme.

Es decir, como primer paso se debería establecermediantesentencia, laresponsabilidad penal del individuo y luego pasar a la extinción del dominio de los bienes que lo ameriten, pues eventualmente se podría llegar al contrasentido de que un individuo resulte afectado por la extinción de dominio de sus bienes, y después no ser declarado culpable en el correspondiente proceso penal, manteniéndose incólume la presunción de inocencia, pero habiéndose ya declarado la extinción de dominio sobre los bienes del procesado.

Es una realidad que si en la práctica se requiriera sentencia penal condenatoria en firme para que procediese la extinción de dominio, esta última bordearía los límites de la ineficacia en la medida que los procesos y las condenas contra narcotraficantes y testaferros no avanzan a la misma velocidad que la indiscriminada concentración de tierra por parte de estos actores del conflicto, en perjuicio de la sociedad colombiana.

Si bien cierto que desligar el proceso de extinción de dominio del proceso de responsabilidad penal puede hacer más eficaz el trámite del primero, esto no puede ser a costa de derechos fundamentales del afectado.

Por ello, es imperativo revisar estos supuestos, de tal modo que sin sacrificar la eficacia de un instrumento como la acción de extinción de dominio, el individuo afectado con ella tenga la posibilidad de recuperar sus derechos reales sobre sus bienes, u obtener una justa indemnización, si con posterioridad el Estado no lograra demostrar la responsabilidad penal del sujeto en las conductas que dieron lugar a la extinción de dominio.

A modo de corolario: perspectivas actuales de la acción de extinción de dominio

Una de las principales críticas que ha recibido la acción de extinción de dominio tiene que ver con los escasos resultados que ha mostrado. Vale decir, que desde el año 2002, cuando se expidió la ley 793 que derogó la ley 333/1996, los resultados en contra del enriquecimiento ilícito han aumentado de manera significativa: a dos mes de entrada en vigor la ley ya se habían producido trece fallos de extinción de dominio de extensas y valiosas propiedades de importantes narcotraficantes como Pablo Escobar, Iván Urdinola Grajales, Hélmer Herrera, entre otros ("Los bienes de los malos", 21 de marzo de 1993).

En vigencia de la ley 793/2003, el panorama de congestión judicial se deteriora de continuo. De acuerdo con la información reflejada en los antecedentes de la ley 1708/2014, al año, el inventario de procesos de extinción de dominio en juicio se incrementa en promedio en 103 casos, lo cual surge de comparar las cifras de ingresos y egresos de procesos (tabla 1). 
Tabla 1

Inventario de procesos de extinción de dominio en etapa de juzgamiento en juzgados penales del Circuito Especializado de Extinción de Dominio de Bogotá D. C.

\begin{tabular}{|ccc|}
\hline Año & Ingresos & $\begin{array}{c}\text { Egresos } \\
\text { con sentencia }\end{array}$ \\
\hline 2004 & 214 & 173 \\
\hline 2005 & 202 & 140 \\
\hline 2006 & 219 & 163 \\
\hline 2007 & 213 & 170 \\
\hline 2008 & 222 & 172 \\
\hline 2009 & 262 & 218 \\
\hline 2010 & 152 & 168 \\
\hline 2011 & 264 & 175 \\
\hline Total & 1.748 & 1.379 \\
\hline
\end{tabular}

Fuente: Congreso de la República de Colombia, Gaceta del Congreso, 724, 16 de septiembre de 2013.

No obstante, en el funcionamiento de la acción de extinción de dominio, el problema más preocupante en la actualidad no parece ser la eficiencia con la que se producen fallos de extinción de dominio, sino, la eficiencia en el manejo estatal de los bienes que han sido objeto de la acción.

La ley 793/2002 dispone que desde la fase inicial de investigación, la Fiscalía puede decretar medidas cautelares de embargo, secuestro y suspensión del poder dispositivo de cualquier tipo de bien, siendo en todo caso designado como secuestre o depositario de los bienes la Dirección Nacional de Estupefacientes ${ }^{7}$, a través del Fondo para la Rehabilitación, Inversión Social y Lucha contra el Crimen Organizado (Frisco), teniendo la facultad de administrarlos, garantizando su productividad, conservación y custodia. La ley 785/2002 establece que los sistemas de administración son: enajenación, contratación, destinación provisional y depósito provisional.

En principio, los bienes objeto de extinción de dominio por enriquecimiento ilícito pueden ser enajenados por el Frisco, de conformidad con lo dispuesto en el artículo
12 de la ley 793/2002 y en el artículo 31 del decreto $3183 / 2011$.

No obstante, la ley 1448/2011, conocida como la Ley de Víctimas, creó el Fondo de la Unidad Administrativa Especial de Gestión de Restitución de Tierras Despojadas, y en el numeral 8 de su artículo 113 erigió como integrante de dicho Fondo a

Las propiedades rurales que hayan sido objeto de extinción de dominio y que se encuentren actualmente bajo la administración de la Dirección Nacional de Estupefacientes, lo mismo que aquellas de las que adquiera la propiedad en el futuro, en las cuantías y porcentajes que determine el Gobierno Nacional (ley 1448/2011, art. 113).

Así, la ley 1448/2011 destina los bienes rurales que son objeto de extinción de dominio -sin discriminar entre una u otra clase de tal acción- al programa de restitución de tierras para las víctimas del conflicto armado.

Lamentablemente lo dispuesto en la norma está aún lejos de materializarse en la realidad. A cifras del año 2005, de 3.376 bienes incautados, solo sobre 170 ya se había emitido sentencia de extinción de dominio; 1.206 habían sido devueltos a sus propietarios o a terceros de buena fe, y sobre 1.870 no existía información de su estado jurídico. El $100 \%$ de estos bienes representaban un aproximado de 421.638 hectáreas (Herrera, 2005, p. 22).

De esta totalidad de bienes incautados, al 2005 el Incoder había destinado con fines de reforma agraria cerca de 5257,4 hectáreas; es decir, solo el 1,2\% del total de la superficie de los predios incautados, lo cual evidencia baja gestión en el cumplimiento de este propósito (Herrera, 2005, p. 25).

La lentitud administrativa en la gestión de estos predios ha generado que muchos de ellos se encuentren en posibilidad real de ser perdidos por el Estado, bien sea por su deterioro 
físico, problemas de índole fiscal frente a impuestos y servicios públicos atrasados, o por inconvenientes jurídicos y sociales, como ocupación por poseedores ad portas de adquirir el dominio por prescripción, la existencia de derechos reales accesorios como hipotecas o prendas, medidas cautelares de terceros como embargos, o la presencia de actores armados en las zonas donde se encuentran los predios, que hacen imposible su entrega a las víctimas del conflicto.

No se puede perder de vista que en el proceso de adjudicación de tierras es necesario, además de establecer la viabilidad del desarrollo de un proyecto productivo, garantizar a los destinatarios de las tierras la realización de dicho proyecto en condiciones de seguridad y dignidad humana (sentencia T-025/2004).

A este panorama se suman los penosos y graves hechos de corrupción que se han descubierto al interior de la Dirección Nacional de Estupefacientes, en los que funcionarios de la entidad han "desaparecido" bienes entregados en procesos de extinción de dominio o han adulterado cifras del valor real de los bienes a subastar ("Policía allanó", 3 de noviembre de 2010).

El problema dista mucho de ser netamente jurídico o administrativo, esto es tan solo una pequeña parte de un grave problema social que afronta el país: la dificultad de la restitución de tierras. Los predios que el Estado puede llegar a recuperar por medio de la extinción de dominio, son solo una fracción del total de tierras que el narcotráfico y los actores del conflicto han obtenido a través de mecanismos ilegales. En 2005, el entonces vicecontralor general de la República, Luis Bernardo Flórez (2005), reveló:

Mediante la compra o apropiación indebida de tierras por narcotraficantes y grupos armados ilegales, en los últimos 20 años se ha realizado la más aberrante concentración de tierra en el país. Una auténtica contrarreforma agraria.
En el documento elaborado por la Contraloría Delegada para Defensa, Justicia y Seguridad se muestran los muy diversos estimativos sobre la compra de tierras por parte de narcotraficantes. Ellos varían así: un mínimo de un millón de hectáreas, equivalente a casi el $3 \%$ del territorio nacional y a un $5 \%$ de las tierras parcialmente explotables. Otros, de cerca de tres millones de hectáreas, como en el trabajo de Roberto Steiner y Alejandra Corchuelo de 1999. Y analistas, como Ricardo Rocha, en su estudio del año 2000, indican que los narcotraficantes poseían más de 4,4 millones de hectáreas que podrían tener un valor de 2.500 millones de dólares (p. 9).

En lo que respecta a la aplicación de la Ley de Víctimas en su componente de restitución de tierras, el panorama no es alentador. Aunque por experiencia personal el autor conoce de primera mano el compromiso y esfuerzo de entidades como la Unidad de Restitución de Tierras, lo cierto es que a marzo 15 de 2014, se han proferido 372 sentencias de restitución y se han devuelto a sus propietarios 20.694 hectáreas (Valencia, 2014), cuando se había proyectado que hacia finales del 2013 se habrán restituido alrededor de 150.000 hectáreas (Valero, 10 de marzo de 2013).

En Colombia existen entre 4,9 y 5,9 millones de personas desplazadas, lo cual representa cerca del $10 \%$ de la población (Herrera, 29 de abril de 2013) y el total de hectáreas por restituir se estima en seis millones (Valencia, 2014). De este modo, resulta sumamente importante ver el proceso de restitución de tierras como la oportunidad histórica de hacer una reforma agraria donde se garantice el acceso a la tierra a las personas que siendo víctimas de la violencia fueron despojadas de ella, y los predios rurales objeto de extinción de dominio pueden ser de gran utilidad en tal labor.

Ahora bien, a partir de la promulgación de la entrada en vigencia de la ley 1708/2014, el manejo de los bienes objeto de extinción de dominio podrá tener cambios decisivos. El artículo 90 de dicha ley señala: 
El Fondo para la Rehabilitación, Inversión Social y Lucha contra el Crimen Organizado (Frisco) es una cuenta especial sin personería jurídica administrada por la Sociedad de Activos Especiales S.A.S. (SAE), sociedad de economía mixta del orden nacional autorizada por la ley, de naturaleza única y sometida al régimen del derecho privado, de acuerdo con las políticas trazadas por el Consejo Nacional de Estupefacientes o su equivalente, con el objetivo de fortalecer el sector justicia, la inversión social, la política de drogas, el desarrollo rural, la atención y reparación a víctimas de actividades ilícitas, y todo aquello que sea necesario para tal finalidad.

De igual forma, el Presidente de la República expedirá, dentro de los doce (12) meses siguientes a la entrada en vigencia de este Código, el reglamento para la administración de los bienes. Dicho reglamento deberá tener en cuenta las normas previstas en este título (ley 1708/2014, art. 90).

Por su parte, el artículo 91 de la misma ley, determina que los bienes objeto de extinción de dominio se utilizarán, en primer lugar, para el pago del pasivo del Fondo y el sostenimiento de la entidad encargada de la administración de los bienes, y descontado ello, se destinará un $25 \%$ a la Rama Judicial y en un $25 \%$ a la Fiscalía General de la Nación, para proyectos de inversión previamente aprobados por el Ministerio de Hacienda y Crédito Público; y el $50 \%$ restante para el Gobierno Nacional, quien reglamentará la distribución de este último porcentaje. Aclara la norma que

En todo caso, los predios rurales sobre los que recaiga la acción de extinción de dominio serán destinados a los programas de generación de acceso a tierra administrados por el Gobierno Nacional. Su régimen de administración y destinación será reglamentado por el Presidente de la República (ley 1708/2014, art. 91).

Habrá que esperar unos años para medir el impacto que la ley 1708/2014 tenga en el panorama de congestión judicial de los procesos de extinción de dominio, la historia nos ha mostrado que no por solo cambiar la norma, la justicia acelera su curso. Empero, el que se haya unificado y cohesionado los procedimientos y reglas aplicables al proceso de extinción de dominio en un código especializado, es una muestra de madurez de una figura jurídica que junto con el respectivo fortalecimiento de las instituciones de investigación y juzgamiento, podrá derivar en un importante mejoramiento en el funcionamiento de la acción de extinción de dominio ${ }^{8}$.

Por otro lado, en lo que respecta al manejo de los bienes objeto de extinción de dominio, es indudable que la eficiente administración de los mismos impactará en el sistema, pues ahora tanto la Rama Judicial como la Fiscalía se beneficiarán del producto de dichos bienes.

Así mismo, la extinción de dominio puede ser una herramienta para incentivar un proceso real y efectivo de reparación y restitución a las víctimas del conflicto, al ser un canal a través del cual se obtengan propiedades rurales para ser entregadas a los beneficiarios del proceso de restitución. La clave de este último punto estará en la reglamentación que se haga de la ley 1708/2014. Si a través de la reglamentación de la ley, el Gobierno Nacional crea un sistema eficiente de administración de estos recursos, se podrá superar uno de los principales escollos de la extinción de dominio en la praxis.

\section{Notas}

1 El mencionado artículo 1 de la ley 200/1936 dispone: "Se presume que no son baldíos, sino de propiedad privada, los fundos poseídos por particulares, entendiéndose que dicha posesión consiste en la explotación económica del suelo por medio de hechos positivos propios de dueño, como las plantaciones o sementeras, la ocupación con ganados y otros de igual significación económica.

El cerramiento y la construcción de edificios no constituyen por sí solos pruebas de explotación económica pero sí pueden conside- 
rarse como elementos complementarios de ella. La presunción que establece este artículo se extiende también a las porciones incultas cuya existencia se demuestre como necesaria para la explotación económica del predio, o como complemento para el mejor aprovechamiento de este, aunque en los terrenos de que se trate no haya continuidad o para el ensanche de la misma explotación. Tales porciones pueden ser conjuntamente hasta una extensión igual a la mitad de la explotada y se reputan poseídas conforme a este artículo".

${ }^{2}$ El artículo 52 de la ley 160/1994 señala: "Establécese en favor de la nación la extinción del derecho de dominio o propiedad sobre los predios rurales en los cuales se dejare de ejercer posesión en la forma establecida en el artículo 1o. de la ley 200/1936, durante tres (3) años continuos, salvo fuerza mayor o caso fortuito, o cuando los propietarios violen las disposiciones sobre conservación, mejoramiento y utilización racional de los recursos naturales renovables y las de preservación y restauración del ambiente, o cuando los propietarios violen las normas sobre zonas de reserva agrícola o forestal establecidas en los planes de desarrollo de los municipios o distritos con más de 300.000 habitantes.

También será causal de extinción de derecho de dominio la destinación del predio para la explotación con cultivos ilícitos. El procedimiento respectivo se iniciará de oficio o a solicitud de autoridad competente. [...]".

${ }^{3}$ Aunque en principio esta función se asignó al Instituto Colombiano de la Reforma Agraria (Incora), esta entidad se suprimió mediante el decreto 1292/2003, creándose en su lugar el Incoder a través del decreto 1300/2003, modificado por medio del decreto 3759/2009.

${ }^{4}$ En todo caso, el artículo 218 de la señalada ley 1708/2014 aclara que "el artículo 18 de la ley 793/2002, y los artículos 9 y 10 la ley 785/2002, seguirán vigentes".

${ }^{5}$ En los debates que dieron lugar a la aprobación de la ley 1708/2014, se afirmó que en pro- medio un proceso de extinción de dominio tarda siete años y once días en la Sala de Extinción de Dominio y Enriquecimiento Ilícito del Tribunal Superior de Bogotá D. C.; la etapa de juicio demora en promedio dos años y siete meses, y el ciclo a cargo de la Fiscalía (fase inicial y fase de investigación) se dilata en promedio cuatro años, cinco meses y veintiocho días (c.f. Congreso de la República de Colombia, Gaceta del Congreso, 905, 12 de noviembre de 2013).

${ }^{6}$ Resulta muy interesante la introducción de la medida cautelar denominada "toma de posesión", pues define de manera contundente, por lo menos para el proceso de extinción de dominio, la posibilidad de que la posesión, sin ser un derecho real, sea objeto de una medida cautelar. En el campo civil ha sido posición de algunos autores sostener la posibilidad de un "embargo o secuestro de la posesión", siendo tales medidas cautelares, en nuestra opinión, posibles sobre derechos y no sobre hechos con consecuencias jurídicas como la posesión, en todo caso, al no ser este el tema que ocupa nuestros argumentos sobre el particular, se desarrollarán en otro escenario.

${ }^{7}$ Mediante el decreto 3183 de 2 de septiembre de 2011, el Gobierno Nacional "dispuso la supresión y liquidación de la Dirección Nacional de Estupefacientes, trasladando la función de administración del Fondo para la Rehabilitación, Inversión Social y Lucha contra el Crimen Organizado (Frisco) al Ministerio de Justicia y del Derecho". Empero, de manera transitoria y durante un año, la Dirección Nacional de Estupefacientes -en liquidación- continuó ejerciendo esta labor, en los términos del decreto 0319 de 7 de febrero de 2012, plazo que se prorrogó hasta 31 de diciembre de 2013 a través el decreto 1420/2012.

${ }^{8}$ Vale la pena resaltar que Colombia se está posicionando como líder internacional en el tema de extinción de dominio, y esto se verifica en hechos como los importantes aportes que autoridades colombianas efectuaron en la 
redacción de la Ley Modelo sobre Extinción de Dominio creada por la Oficina de las Naciones Unidas contra la Droga y el Delito (UNODC, por su sigla en inglés).

\section{Referencias}

Acto Legislativo 01 de 1936. Diario Oficial No. 23.263. Congreso de la República, agosto de 1936.

Camargo, P. (2009). La acción de extinción del dominio. Bogotá: Leyer.

Código Civil Colombiano. (2014). Congreso de la República.

Constitución Política de Colombia (1886). Congreso de la República.

Constitución Política de Colombia (1991). Congreso de la República.

Decreto 2665 de 1994. Por el cual se reglamenta el Capítulo X1 de la Ley 160 de 1994, relacionado con la extinción del derecho de dominio privado sobre inmuebles rurales. Diario oficial No. 41627. Ministerio de Agricultura y Desarrollo Rural, diciembre de 1994.

Decreto 1292 de 2003. Por el cual se suprime el Instituto Colombiano de la Reforma Agraria, Incora y se ordena su liquidación. Diario oficial $\mathrm{N}^{\circ}$. 45196. Ministerio de Hacienda y Crédito Público, mayo de 2003.

Decreto 1300 de 2003. Por el cual se crea el Instituto Colombiano de Desarrollo Rural, Incoder y se determina su estructura. Diario oficial N ${ }^{\circ} .45196$. Ministerio de Agricultura y Desarrollo Rural, mayo de 2003.

Decreto 3759 de 2009. Por el cual se aprueba la modificación de la estructura del Instituto Colombiano de Desarrollo Rural - INCODER y se dictan otras disposiciones. Dia- rio Oficial $\mathrm{N}^{\circ}$ 47.488. Ministerio de Agricultura y Desarrollo, septiembre de 2009.

Decreto 3183 de 2011. Por el cual se suprime la Dirección Nacional de Estupefacientes, se ordena su liquidación y se dictan otras disposiciones. Diario oficial No. 48180. Ministerio de Justicia y Derecho, septiembre 2011.

Decreto 0319 de 2012. Por el cual se adiciona un numeral 21 al artículo 6 y se modifica el inciso primero del parágrafo segundo del artículo 30 del Decreto 3183 de 2011, y se adiciona un parágrafo transitorio al artículo 10 del Decreto 1170 de 2008. Diario Oficial $\mathrm{N}^{\circ}$ 48.336. Ministerio de Justicia y del Derecho, febrero de 2012.

Decreto 1420 de 2012. Por el cual se prorroga el plazo de liquidación de la Dirección Nacional de Estupefacientes en liquidación. Diario Oficial $\mathrm{N}^{\circ}$ 48.480. Ministerio de Justicia y del Derecho, junio de 2012.

Duguit, L. (1915). Las trasformaciones generales del Derecho Privado desde el Código de Napoleón. Madrid: Francisco Beltrán.

Florez, L. (2005). Extinción de dominio, reforma agraria, democracia y paz. Economía Colombiana., 309, 8-14.

Hernandez, J. (2005). Naturaleza Constitucional de la extinción de dominio. Economía Colombiana, 309, 60-65.

Herrera, N. (29 de abril de 2013). Colombia, el país con más desplazados en el mundo. $E l$ espectador. Recuperado de http://www. elespectador.com/noticias/nacional/ articulo-419205-colombia-el-pais-masdesplazados-elmundo

Herrera, W. (2005). Tierras incautadas para la reforma agraria: restricciones y posibilidades. Economía Colombiana, 309, 15-26. 
Informe de Ponencia Primer debate Proyecto de Ley 283 de 2013 Senado, 263 de 2013 Cámara. Congreso de la Republica de Colombia, Gaceta del Congreso $N^{\circ} 724$, septiembre de 2013.

Informe de Ponencia Segundo debate Proyecto de Ley 283 de 2013 Senado, 263 de 2013 Cámara. Congreso de la Republica de Colombia, Gaceta del Congreso $N^{\circ}$ 905, 12 de noviembre de 2013.

Ley 200 de 1936. Sobre régimen de tierras. Diario Oficial N 23.388. Congreso de la República de Colombia, diciembre de 1936.

Ley 100 de 1944. Sobre régimen de tierras. Diario oficial $\mathrm{N}^{\circ} 25759$. Congreso de la República de Colombia, diciembre de 1944.

Ley 4 de 1973. Por la cual se introducen modificaciones a las Leyes 200 de 1936, 135 de 1961 y 1a de 1968. Se establecen disposiciones sobre renta presuntiva, se crea la Sala Agraria en el Consejo de Estado y se dictan otras disposiciones. Diario oficial $\mathrm{N}^{\circ}$ 33828. Congreso de la República de Colombia, marzo de 1973.

Ley 99 de 1993. Por la cual se crea el Ministerio del Medio Ambiente, se reordena el Sector Público encargado de la gestión y conservación del medio ambiente y los recursos naturales renovables, se organiza el Sistema Nacional Ambiental, SINA, y se dictan otras disposiciones. Diario Oficial $\mathrm{N}^{\circ}$ 41146. Congreso de la República de Colombia, diciembre de 1993.

Ley 160 de 1994. Por la cual se crea el Sistema Nacional de Reforma Agraria y Desarrollo Rural Campesino, se establece un subsidio para la adquisición de tierras, se reforma el Instituto Colombiano de la Reforma Agraria y se dictan otras disposiciones. Diario oficial $\mathrm{N}^{\circ} 41479$. Congreso de la República de Colombia, agosto de 1994.
Ley 333 de 1996. Por la cual se establecen las normas de extinción de dominio sobre los bienes adquiridos en forma ilícita. Diario oficial $N^{\circ}$ 42945. Congreso de la República de Colombia, diciembre de 1996.

Ley 785 de 2002. Por la cual se dictan disposiciones relacionadas con la administración de los bienes incautados en aplicación de las Leyes 30 de 1986 y 333 de 1996. Diario oficial $\mathrm{N}^{\circ} 45046$. Congreso de la República de Colombia, diciembre de 2002.

Ley 793 de 2002. Por la cual se deroga la Ley 333 de 1996 y se establecen las reglas que gobiernan la extinción de dominio. Diario oficial $N^{\circ} 45046$. Congreso de la República de Colombia, diciembre de 2002.

Ley 906 de 2004. Por la cual se expide el Código de Procedimiento Penal. Diario oficial $\mathrm{N}^{\circ}$ 45658. Congreso de la República de Colombia, agosto de 2004.

Ley 1330 de 2009. Por la cual se adiciona la Ley 793 de 2002 y se establece el trámite abreviado y el beneficio por colaboración. Diario oficial $N^{\circ} 47413$. Congreso de la República de Colombia, julio de 2009.

Ley 1395 de 2010. Por la cual se adoptan medidas en materia de descongestión judicial. Diario oficial $\mathrm{N}^{\circ} 47768$. Congreso de la República de Colombia, julio de 2010.

Ley 1448 de 2011. Por la cual se dictan medidas de atención, asistencia y reparación integral a las víctimas del conflicto armado interno y se dictan otras disposiciones. Diario oficial $\mathrm{N}^{\circ} 48096$. Congreso de la República de Colombia, junio de 2011.

Ley 1453 de 2011. Por medio de la cual se reforma el Código Penal, el Código de Procedimiento Penal, el Código de Infancia y Adolescencia, las reglas sobre extinción de dominio y se dictan otras disposiciones en materia de seguridad. Diario oficial 
N 48110. Congreso de la República de Colombia, junio de 2011.

Ley 1564 de 2012. Por medio de la cual se expide el Código General del Proceso y se dictan otras disposiciones. Diario oficial $\mathrm{N}^{\circ}$ 48489. Congreso de la República de Colomba, julio de 2012.

Ley 1708 de 2014. Por medio de la cual se expide el Código de Extinción de Dominio. Diario oficial $\mathrm{N}^{\circ} 49039$. Congreso de la República de Colombia, enero de 2014.

Los bienes de los malos. (21 de marzo de 1993). El Tiempo. Recuperado de http://www.eltiempo.com/archivo/documento/MAM81204.

Martínez, W. (2014). El nuevo Código de Extinción de Dominio. Ámbito Jurídico. Legis.

Oficina de las Naciones Unidas contra la Droga y el Delito -[UNODC]. (2011). Ley Modelo sobre Extinción de Dominio. Bogotá: Naciones Unidas.

Policía allanó la Dirección de Estupefacientes. (3 de noviembre de 2010). El Tiempo. Recuperado de http://www.eltiempo.com/ archivo/documento/CMS-8264642

Sentencia C-374 (1997, agosto 13). Acción de Constitucionalidad. M.P José Gregorio Hernández Galindo. Corte Constitucional.

Sentencia C-1708 (2000, diciembre 12). Acción de Constitucionalidad. M. P. Álvaro Tafur Galvis. Corte Constitucional.

Sentencia C-740 (2003, agosto 28). Acción de constitucionalidad. M. P. Jorge Córdoba Triviño. Corte Constitucional.

Sentencia C-887 (2004, septiembre 14). Acción de Constitucionalidad. M. P. Alfredo Beltrán Sierra. Corte Constitucional.
Sentencia C-030 (2006, enero 26). Acción de Constitucionalidad. M. P. Álvaro Tafur Galvis. Corte Constitucional.

Sentencia C-296 (2011, abril 27). Acción de Constitucionalidad. M. P. María Victoria Calle Correa. Corte Constitucional.

Sentencia C-540 (2011, julio 6). Acción de Constitucionalidad. M. P. Jorge Ignacio Pretelt Chaljub. Corte Constitucional.

Sentencia Extinción de dominio. (1999, septiembre 21) Proceso No 0146, M. P. Jorge Enrique Córdoba Poveda. Corte Suprema de Justicia, Sala Plena.

Sentencia Extinción de dominio. (2006, abril 26). Proceso $N^{\circ}$. 18682, M. P. Jorge Luis Quintero Milanés. Corte Suprema de Justicia, Sala de Casación Penal.

Sentencia T-025 (2004, enero 22). Acción de tutela. M. P. Manuel José Cepeda Espinosa. Corte Constitucional.

Sentencia T-076 (2011, febrero 8). Acción de Tutela. M. P. Luis Ernesto Vargas Silva. Corte Constitucional.

Solano, J. (2004). La expropiación. Bogotá: Ediciones Doctrina y Ley.

Valencia. L. (29 de 03 de 2014). Presidente Santos ¡Salve la restitución de tierras! Revista Semana. Recuperado de http:// www.semana.com/opinion/articulo/leonvalencia-presidente-santos-salve-la-restitucion-de-tierras/381914-3

Valero, D. (10 de marzo de 2013). La mayor restitución de tierras por vía judicial en el país. El tiempo. Recuperado de: http://www. eltiempo.com/politica/ARTICULO-WEBNEW_NOTA_INTERIOR-12672352.html 